\title{
Association between metabolic syndrome and prognosis of breast cancer: a meta-analysis of follow-up studies
}

Peiting $\mathrm{Li}^{1}$, Tianying Wang ${ }^{2}$, Chen Zeng ${ }^{1}$, Meng Yang ${ }^{1}$, Gang Li ${ }^{1}$, Jiang Han ${ }^{1}$ and Wei $\mathrm{Wu}^{1 *}$

\begin{abstract}
Background: Metabolic syndrome (MetS) has been suggested to be a risk factor for many cancers, including breast cancer. However, it remains unclear whether MetS predicts poor prognosis in women with breast cancer. A meta-analysis was performed to summarize the association between MetS and clinical outcome in women with breast cancer.

Methods: Cohort studies were identified by search of PubMed and Embase databases. A random-effect model incorporating the potential heterogeneity was applied to pool the results. Subgroup analyses according to the ethnicity and study design were performed.

Results: Nine cohort studies with 17,892 women with breast cancer were included. Pooled results showed that MetS was significantly associated with an increased risk of breast cancer recurrence (adjusted risk ratio [RR] $=1.52,95 \%$, $p=0.02$ ). Subgroup analyses showed that Met $S$ was independently associated with increased recurrence of breast cancer in Caucasians (adjusted $R R=1.75, p=0.02$ ), but not in Asians (adjusted $R R=1.07, p=0.81$ ), and MetS was associated with a trend of increased risk of breast cancer recurrence in both the prospective and retrospective studies. Although we failed to show a significant association between MetS and breast cancer related deaths (adjusted $R R=1.24, p=0.41$ ), MetS was associated with increased risk of all-cause deaths in these patients (adjusted $R R=1.80$, $p<0.001$ ).
\end{abstract}

Conclusions: MetS may predict the risk of cancer recurrence and mortality in women with breast cancer, particularly in Caucasians.

Keywords: Metabolic syndrome, Breast cancer, Recurrence, Mortality, Meta-analysis

\section{Background}

Despite of the improvements in the prevention and management of cancer, breast cancer remains a common malignancy in women, and about 1.4 million women are diagnosed with breast cancer annually [1-3]. Metabolic disorders, such as obesity and insulin resistance, have been suggested to be involved in the pathogenesis and

\footnotetext{
*Correspondence: wwxy399_b@163.com

1 Department of Breast Thyroid Surgery, The Third Xiangya Hospital of Central South University, No. 172 Tong Zi Po Road, Changsha 410013, China

Full list of author information is available at the end of the article
}

progression of breast cancer [4-6]. Metabolic syndrome (MetS), which indicates a cluster of metabolic abnormalities including abdominal adiposity, insulin resistance, hyperglycemia, hypertension, and dyslipidemia [7-10], has been considered to be a risk factor of a variety of cancers, including breast cancer in postmenopausal women $[11,12]$. In addition, MetS have been proposed as a prognostic factor in women with breast cancer. Particularly, MetS has been associated with more aggressive tumor biology of breast cancer [13, 14], and some studies showed that MetS is associated with higher risk of recurrence and mortality in these patients [15-18]. However, other cohort studies failed to show a significant

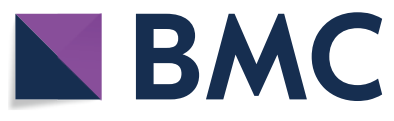

(c) The Author(s) 2020. This article is licensed under a Creative Commons Attribution 4.0 International License, which permits use, sharing, adaptation, distribution and reproduction in any medium or format, as long as you give appropriate credit to the original author(s) and the source, provide a link to the Creative Commons licence, and indicate if changes were made. The images or other third party material in this article are included in the article's Creative Commons licence, unless indicated otherwise in a credit line to the material. If material is not included in the article's Creative Commons licence and your intended use is not permitted by statutory regulation or exceeds the permitted use, you will need to obtain permission directly from the copyright holder. To view a copy of this licence, visit http://creativeco mmons.org/licenses/by/4.0/. The Creative Commons Public Domain Dedication waiver (http://creativecommons.org/publicdomain/ zero/1.0/) applies to the data made available in this article, unless otherwise stated in a credit line to the data. 
association between MetS and poor clinical outcomes in women with breast cancer [19-23]. Moreover, whether factors such as ethnicity and study design affects the association between MetS and prognosis in women with breast cancer remains to be determined [24]. Therefore, in this study, we performed a meta-analysis to evaluate the potential association between MetS and risks of recurrence or death in women with breast cancer.

\section{Methods}

The meta-analysis was designed and performed in accordance with the MOOSE (Meta-analysis of Observational Studies in Epidemiology) [25] and Cochrane's Handbook [26] guidelines.

\section{Literature search}

Electronic databases of PubMed and Embase were systematically searched using the combination of the following terms: (1) "metabolic syndrome" OR "insulin resistance syndrome" OR "syndrome X"; (2) "breast cancer"; and (3) "survival" OR "prognosis" OR "mortality" OR "death" OR "recurrence" OR "surgery" OR "operation". The search was limited to human studies without restriction of the publication language. The reference lists of original and review articles were also analyzed manually. The final literature search was performed on August 24, 2019.

\section{Study selection}

Studies were included if they met the following criteria: (1) published as full-length article; (2) designed as cohort studies with the minimal follow-up duration of 1 year; (3) included women with breast cancer; (4) MetS was identified as exposure of interest at baseline; (5) documented the incidence of at least one of the outcomes during follow-up, including the primary outcome of breast cancer recurrence, and the secondary outcomes of breast cancer related deaths and all-cause deaths; and (6) reported the adjusted risk ratios (RRs, at least adjusted for age) and their corresponding 95\% confidence intervals (CIs) for the above outcomes comparing breast cancer women with and without MetS. Definitions of MetS were consistent with that was applied in the original studies. Reviews, editorials, preclinical studies, and non-cohort studies were excluded.

\section{Data extracting and quality evaluation}

Literature search, data extraction, and study quality assessment were independently performed by two authors according to the predefined inclusion criteria. If inconsistencies occurred, discussion with the corresponding author was suggested to resolve these issues. The following data were extracted: (1) name of the first author, publication year, study location, and study design; (2) characteristics and numbers of women with breast cancer, ethnic groups, criteria for the diagnosis of MetS, and follow-up period; and (3) number of cases with breast cancer recurrence, breast cancer related deaths, and all-cause deaths during follow-up, and variables adjusted when presenting the RRs. The quality of each study was evaluated using the Newcastle-Ottawa Scale (NOS) [27]. This scale ranges from 1 to 9 stars and judges the quality of each study regarding three aspects: selection of the study groups; the comparability of the groups; and the ascertainment of the outcome of interest.

\section{Statistical analyses}

The association between MetS and breast cancer recurrence or mortality outcome was measured by RRs in this study. To stabilize its variance and normalize the distribution, RR data and its corresponding stand error (SE) from each study was logarithmically transformed [26]. The Cochrane's $Q$ test was performed to evaluate the heterogeneity among the include cohort studies [26, 28], and the $\mathrm{I}^{2}$ statistic was also calculated. A significant heterogeneity was considered if $\mathrm{I}^{2}>50 \%$. A random effect model was used to pool the results since this model has been indicated to incorporate the potential heterogeneity of the included studies and therefore could provide a more generalized result. Sensitivity analysis by omitting one study at a time was performed to evaluate the stability of the results [26]. To evaluate the influences of ethnicity and study design on the outcome, predefined subgroup analyses were performed [29]. Potential publication bias was assessed by visual inspection of the symmetry of the funnel plots, complemented with the Egger regression test [30]. The RevMan (Version 5.1; Cochrane Collaboration, Oxford, UK) and STATA software were used for the statistics.

\section{Results \\ Literature search}

The flowchart of database search was shown in Fig. 1. Briefly, 472 studies were obtained from database search, and 443 of them were excluded primarily due to the irrelevance to the objective of the study. For the remaining 29 potential relevant studies that underwent full text review, 20 were further excluded because eight of them were not cohort studies, two did not include MetS as exposure of interest, eight included patients without breast cancer at baseline, and the other two were repeated abstracts of the included studies. Finally, nine follow-up studies were included [15-23]. 


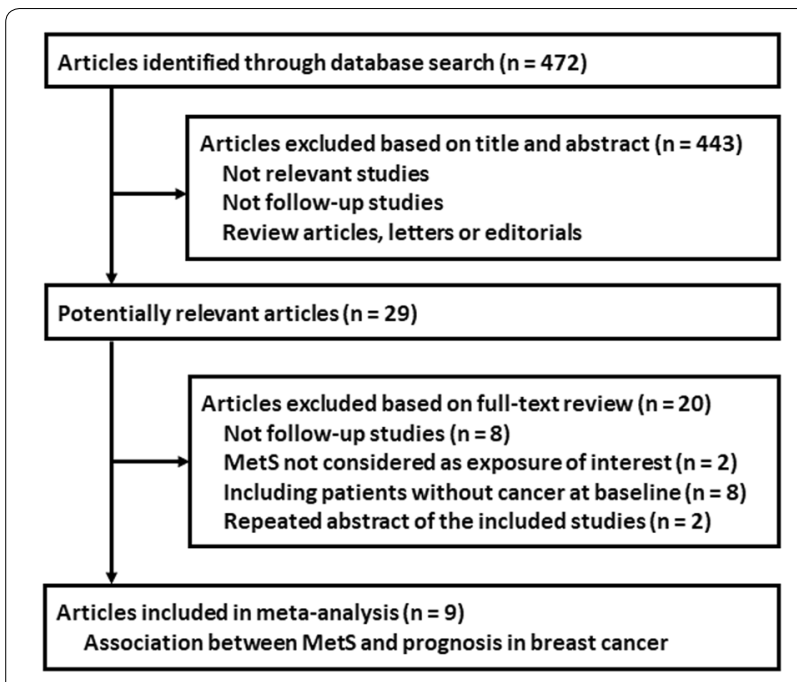

Fig. 1 Flowchart of database search and study inclusion

\section{Study characteristics and quality}

Overall, this meta-analysis included nine cohort studies [15-23] with 17,892 women with breast cancer. Since three studies provided data based on the status of hormone receptors (HR) of the cancer $[16,19,20]$ and one study based on age stratification [22], these datasets were included separately. The characteristics of the included cohorts were shown in Table 1 . Three of them were prospective cohort studies $[15,18,19]$, while the other six were retrospective cohort studies [16, 17, 20-23]. All of these studies included breast cancer women who received anti-cancer therapy and were with no signs of recurrence at baseline. Among them, 2583 women (14.4\%) were diagnosed as MetS at baseline according to the criteria of the revised National Cholesterol Education Program's Adults Treatment Panel III (NCEP-ATP III), the International Diabetes Federation (IDF), American Association of Clinical Endocrinologists (AACE), and American Heart Association (AHA)/National Heart, Lung, and Blood Institute (NHLBI) [31-34]. The mean follow-up durations varied from 2.4 to 11.1 years, and outcomes of breast cancer recurrence, breast cancer related deaths, and all-cause deaths were reported. Potential confounding factors, including age, cancer stage at diagnosis, HR status, and treatment were adjusted to a varying degree in the included studies. The qualities of the included follow-up studies were generally good, with the NOS ranging from seven to nine points (Table 2).

\section{Association between MetS and recurrence risk of breast cancer}

Ten datasets from seven cohort studies [15-17, 19-21, 23] were included for the meta-analysis of the association

between MetS and recurrence risk in women with breast cancer. Moderate heterogeneity was detected ( $p$ for Cochrane's Q test $=0.12, \mathrm{I}^{2}=36 \%$ ). Pooled results with a random-effect model showed that MetS at baseline was significantly associated with increased recurrence risk of breast cancer (adjusted $R R=1.52,95 \%$ CI 1.08 to 2.13 , $\mathrm{p}=0.02$; Fig. 2). Results of sensitivity analyses by omitting one study at a time did not significantly change the results (adjusted RR: 1.44 to $1.64, \mathrm{p}$ all $<0.05$ ), suggesting the robustness of the finding. Subgroup analysis by the ethnicity of the included women showed that MetS was independently associated with increased recurrence risk of breast cancer in Caucasians (five datasets, adjusted $\mathrm{RR}=1.75,95 \% \mathrm{CI} 1.07$ to $2.85 ; \mathrm{p}=0.02$ ), but not in Asians (five datasets, adjusted $R R=1.07,95 \%$ CI 0.64 to $1.79 ; \mathrm{p}=0.81$; Fig. 3a). Subgroup analyses according to the study design showed that MetS was associated with a trend of increased recurrence risk of breast cancer in both the prospective and retrospective cohort studies (Fig. 3b).

\section{Association between MetS and mortality risk in women with breast cancer}

Meta-analysis of two studies $[17,18]$ showed that MetS was not significantly associated with increased risk of breast cancer related deaths (adjusted $\mathrm{RR}=1.24,95 \% \mathrm{CI}$ 0.74 to $2.09 ; \mathrm{p}=0.41 ; \mathrm{I}^{2}=63 \%$; Fig. $\left.4 \mathrm{a}\right)$. However, metaanalysis of six datasets from four studies [17, 18, 20, 22] showed that MetS was significantly associated with an increased risk of all-cause deaths in women with breast cancer (adjusted $\mathrm{RR}=1.80,95 \% \mathrm{CI} 1.54$ to $2.10 ; \mathrm{p}<0.001$; $\mathrm{I}^{2}=0 \%$; Fig. 4b).

\section{Publication bias}

The funnel plots for the association between MetS and risks of recurrence and all-cause deaths in women with breast cancer were shown in Fig. 5a, b. The plots were symmetrical on visual inspection, suggesting low risks of publication biases. Results of Egger's regression tests also showed similar results ( $\mathrm{p}=0.542$ and 0.344 , respectively). Publication bias for the meta-analysis of the association between MetS and risk of breast cancer related deaths was difficult to estimate since only two studies were included.

\section{Discussion}

In this meta-analysis of longitudinal follow-up studies, we found that MetS in women with breast cancer may predict poor clinical prognosis. Specifically, MetS was associated with an increased risk of breast cancer recurrence, even after controlling of potential confounding factors including age, disease stage at diagnosis, HR status, and treatments. Moreover, we found that the 


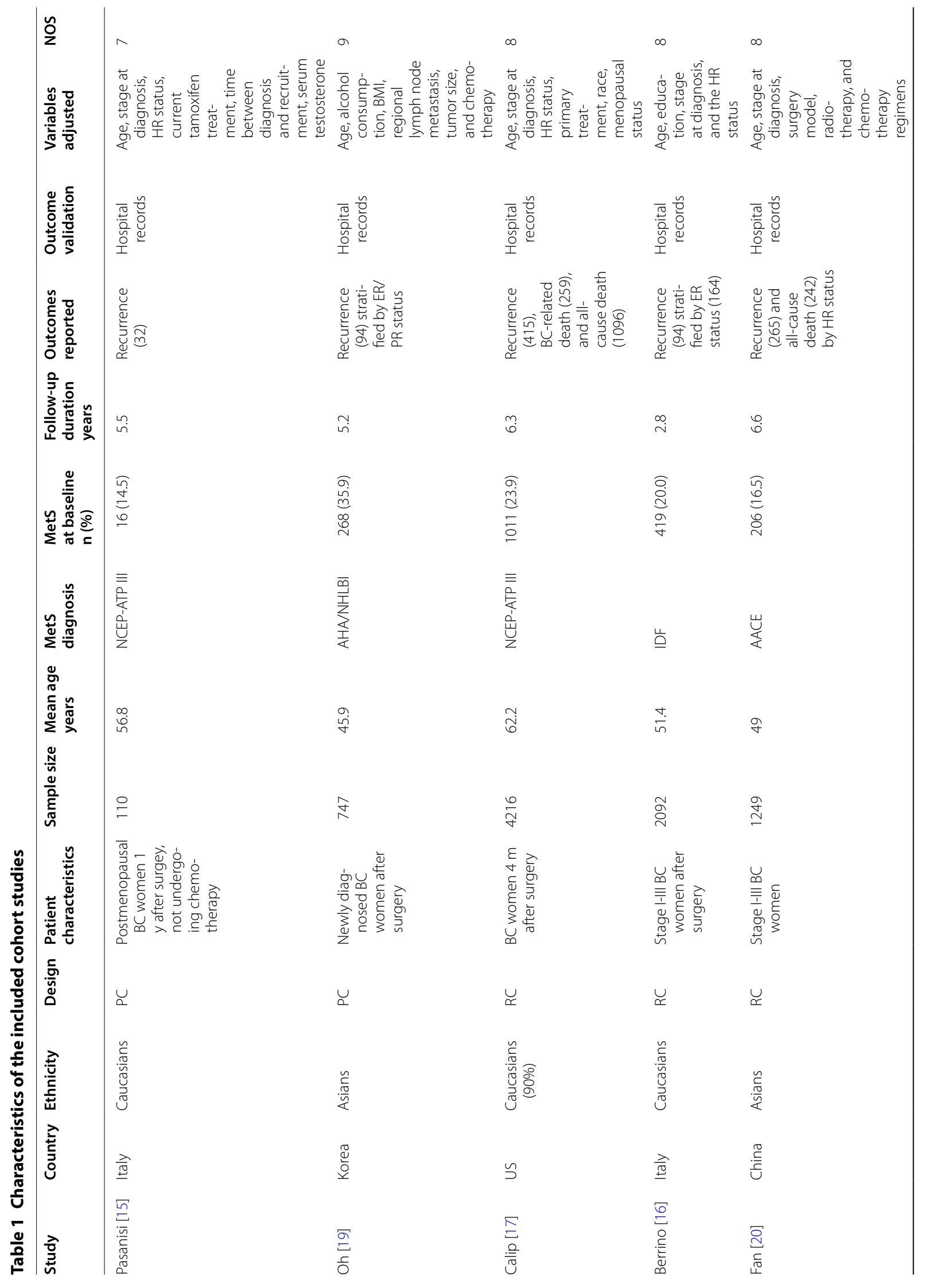




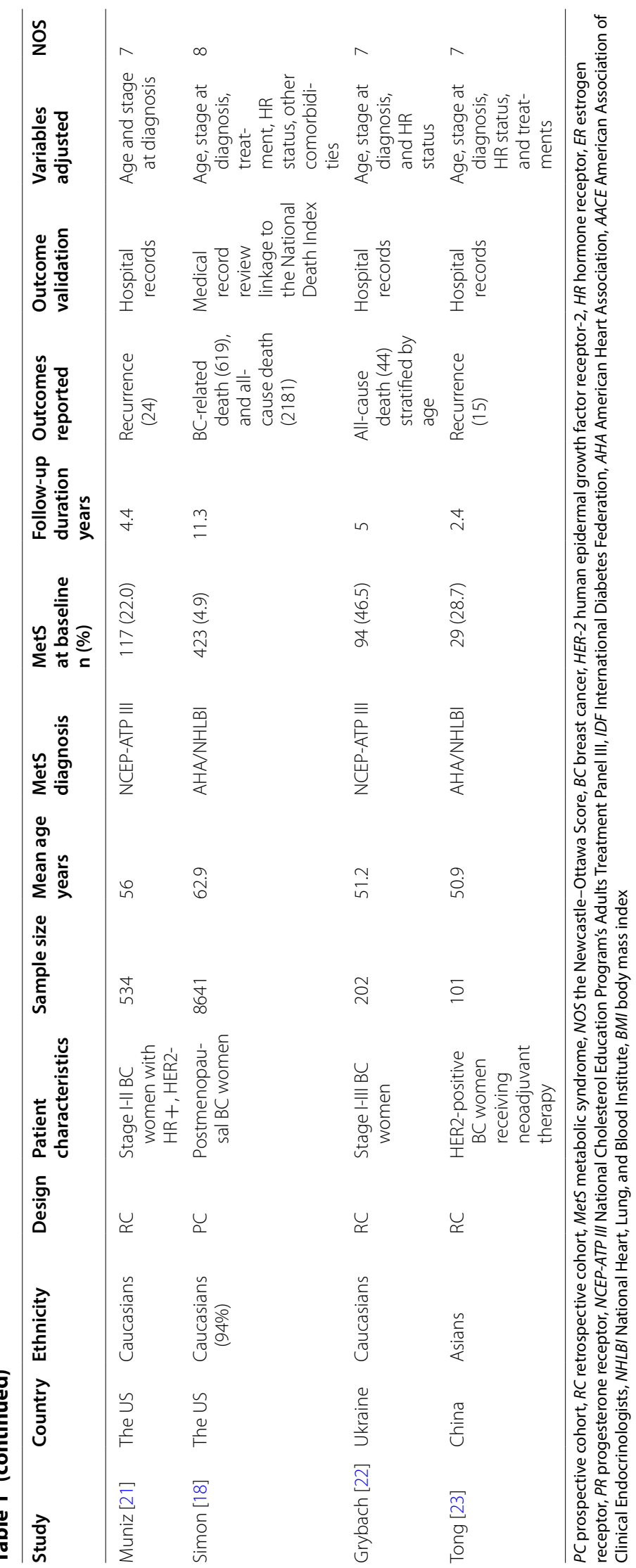




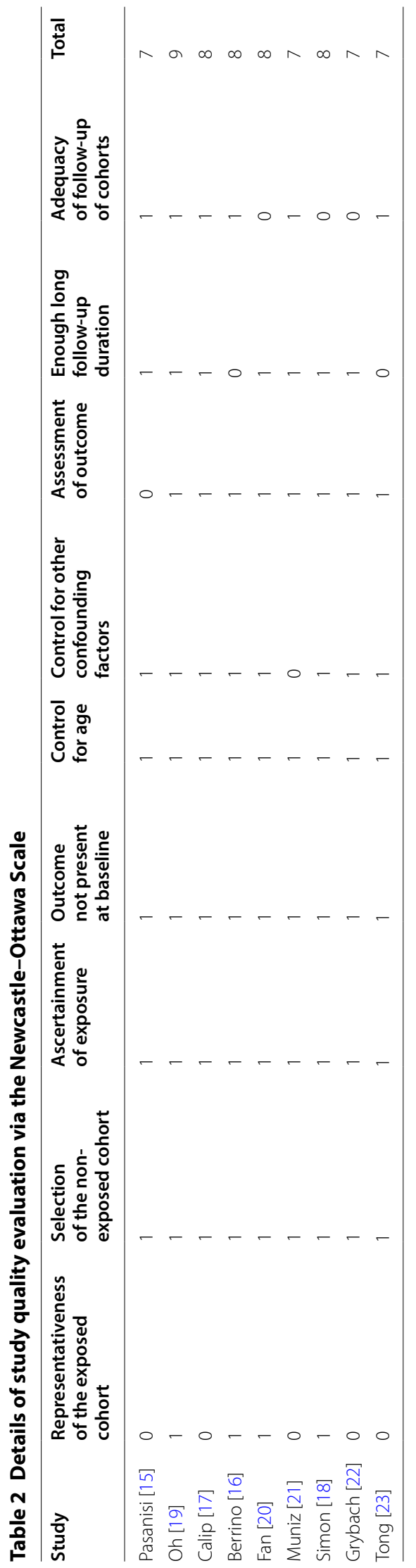




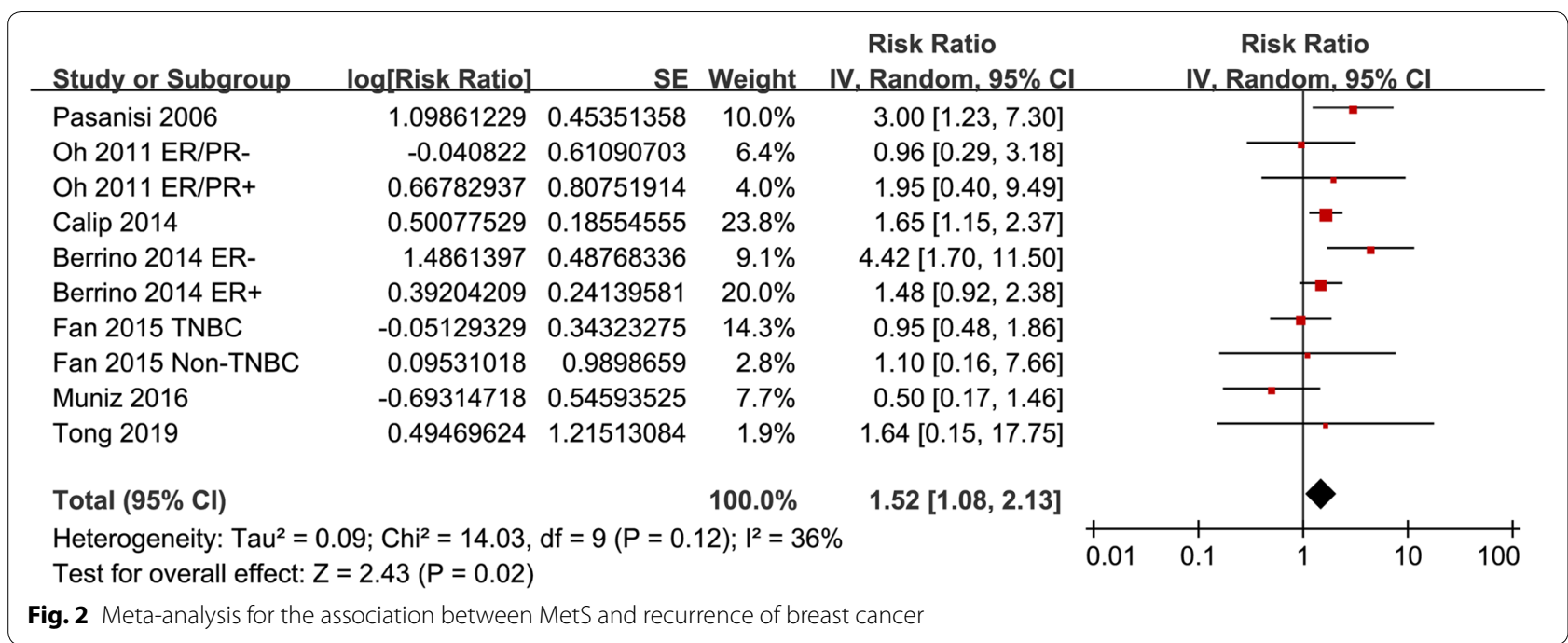

association between MetS and increased recurrence risk of breast cancer was significant in studies including Caucasians, but not in Asians. In addition, although a significant association between MetS and breast cancer related deaths was not retrieved by meta-analysis of only two studies, we found that MetS was significantly associated with increased all-cause deaths in women with breast cancer. These results demonstrated that MetS may be a prognostic factor in women with breast cancer, which may predict higher risk of overall mortality.

To the best of our knowledge, our study is the first meta-analysis to evaluate the potential association between MetS and clinical outcomes in women with breast cancer. By combining the results of multivariableadjusted data, results of our study showed that MetS in women with breast cancer is associated with higher recurrence risk and overall mortality, which is independent of some known prognostic factors, such as age, disease stages, and HR status. These results highly indicated that MetS may be an independent predictor of poor prognosis in women with breast cancer. These findings should be validated in large-scale prospective cohort studies, and clinical studies are needed to determine whether optimized management of MetS in women with breast cancer could improve their clinical outcomes. Another interesting finding of the study is that our subgroup analysis showed that MetS is associated with a higher recurrence risk of breast cancer in Caucasian women, but not in Asian women. Although the mechanisms underlying the potential racial difference between the association of MetS and prognosis in breast cancer remain undetermined, some previous studies did indicate a potential racial difference regarding the influence of comorbidities on the survival in women with breast cancer. A previous retrospective cohort study using the Surveillance, Epidemiology and End Results-Medicare linked data showed that diabetes was associated with increased breast cancer-specific mortality in white women, but not in the other ethnicities [35]. Moreover, previous studies indicated that prevalence of breast cancer subtypes varied by race/ethnicity [36, 37], which may also be the reason of the potential mechanism underlying the racial difference between the association of MetS and prognosis in women with breast cancer. Further studies investigating the potential mechanisms are warranted.

The potential pathophysiological mechanisms underlying the association between MetS and poor prognosis in breast cancer may be multifactorial. Previous clinical studies showed that MetS may be associated with more aggressive tumor biology of breast cancer [13, 14], although different findings are also shown from another study [38]. Insulin resistance and chronic inflammation are the characterized pathophysiological features in MetS [39]. Experimental studies showed that insulin resistance could lead to compensatory hyperinsulinemia, which enhanced the cross-binding of insulin to the insulin-like growth factor-1 (IGF-1) receptors expressed on breast epithelial cells [40]. The activated IGF-1 pathway may stimulate the carcinogenesis and progression of breast cancer [40]. Moreover, hyperinsulinemia may also accelerate the progression of breast cancer by stimulation of hepatic IGF-1 synthesis and inhibition the hepatic expression of IGF-1 receptors, leading to an increased circulating IGF-1 level [40]. Also, the chronic low-grade inflammation in MetS patients has also been involved in the development and aggression of many malignancies, including breast cancer [41]. A previous study in obesity-resistant BALB/c strain of female mice showed 


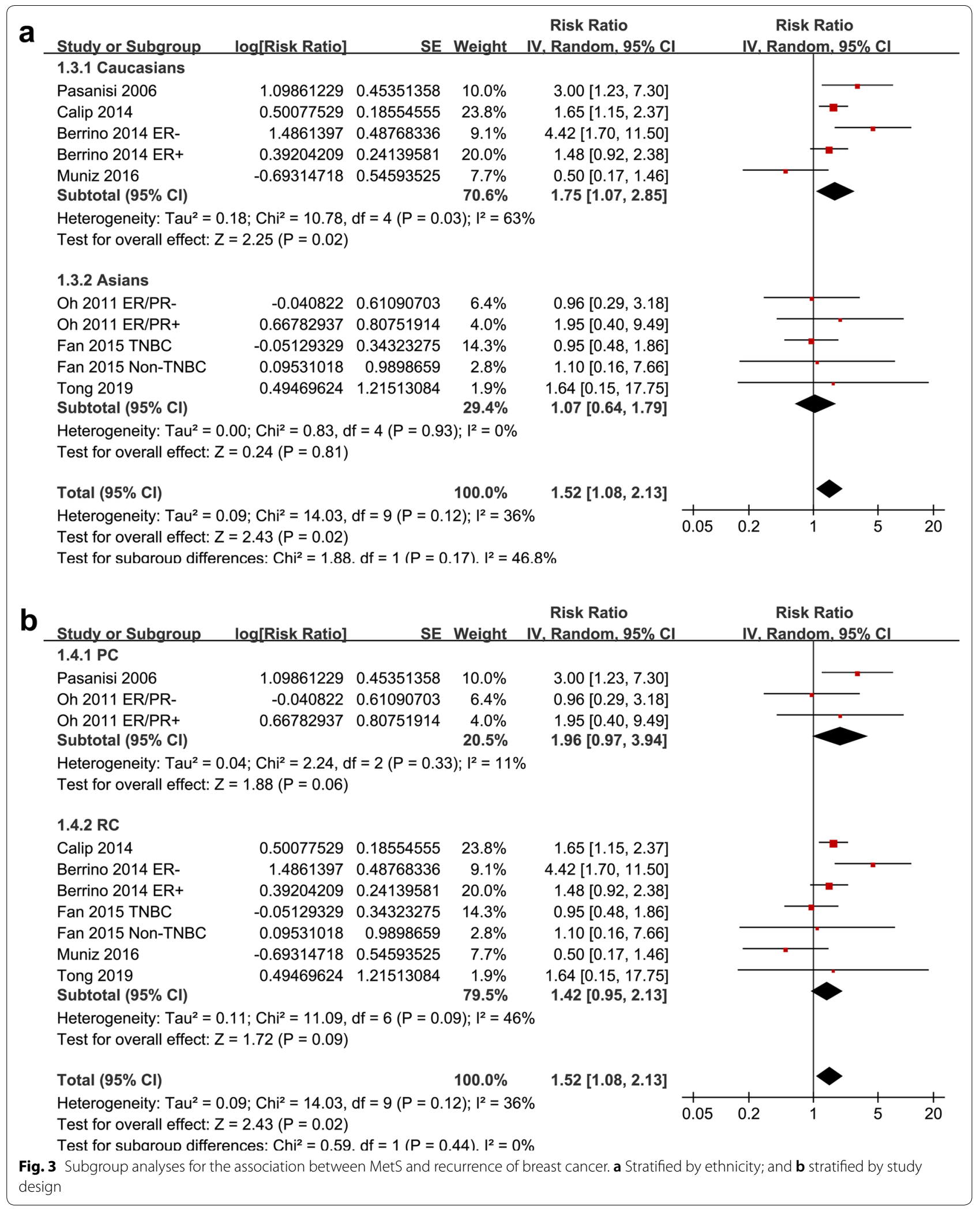




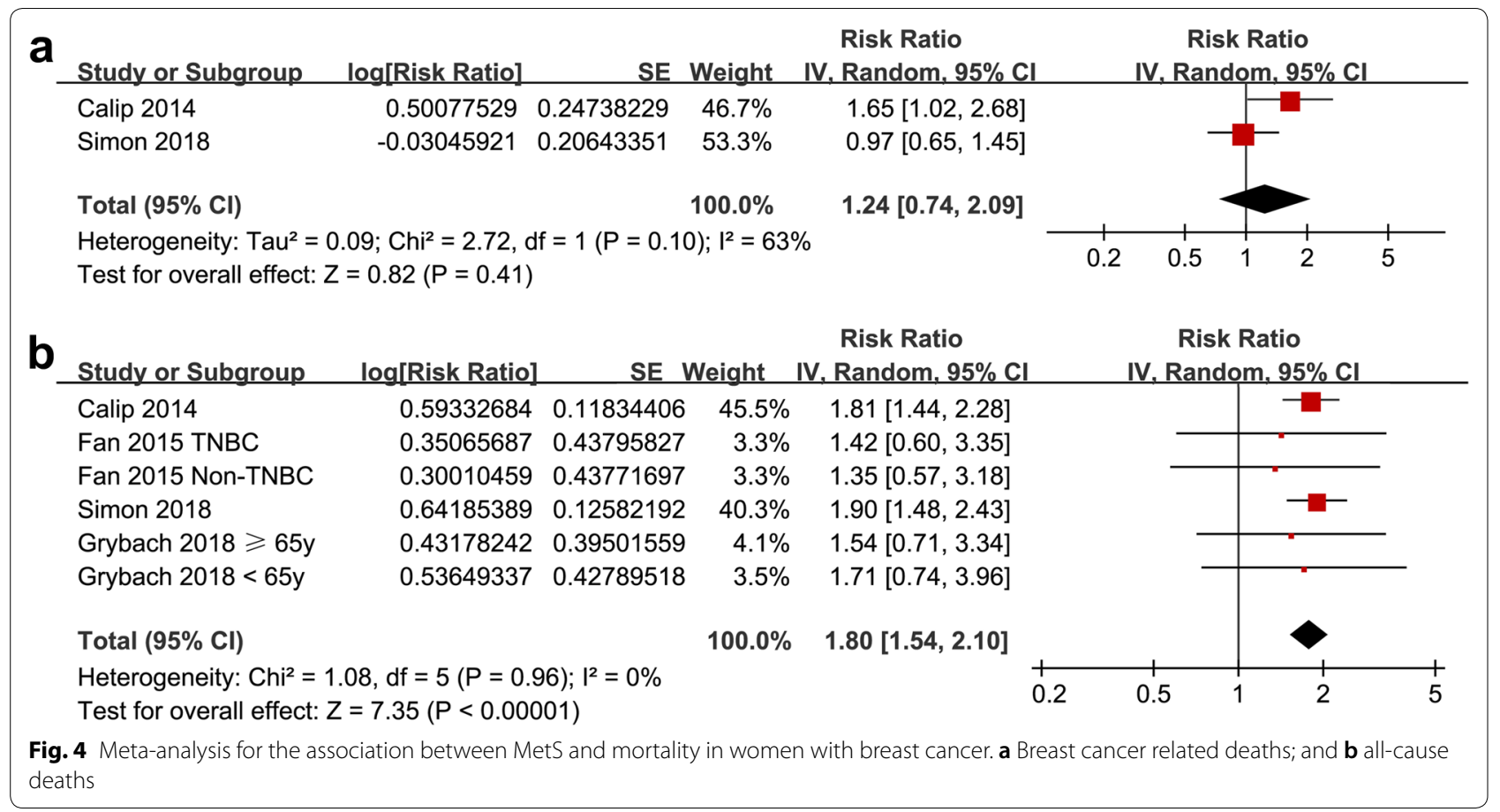

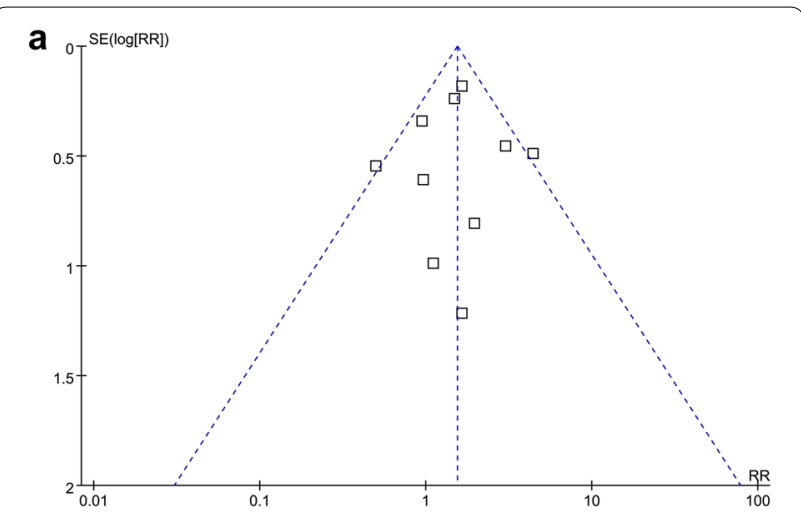

b

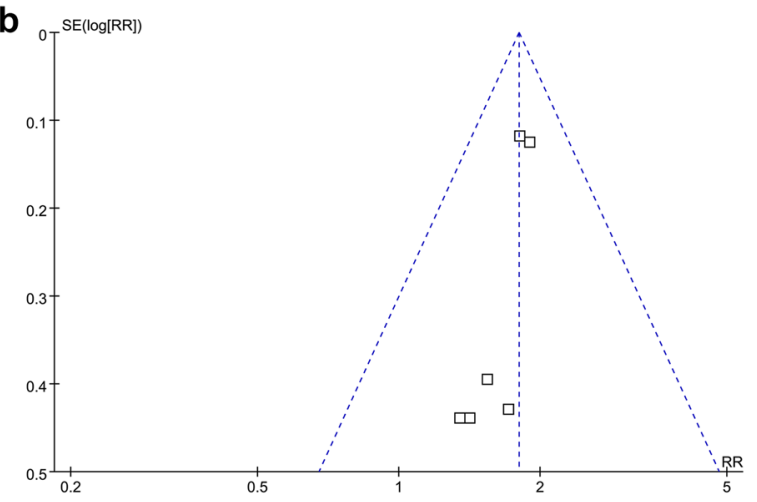

Fig. 5 Funnel plots for the meta-analyses of the association between MetS and prognosis of breast cancer. a recurrence of breast cancer; and $\mathbf{b}$ all-case deaths that a high-fat diet could stimulate growth of an estrogen receptor (ER) -negative murine mammary carcinoma cell line, and its metastasis from the orthotropic injection site to the lungs and liver. This accelerated cancer progression was accompanied by enhanced tumor-related angiogenesis and increased serum concentrations of several proinflammatory cytokines, including interleukin 6 , and leptin, which suggested the potential association between MetS, inflammation, and cancer invasion [42]. Moreover, in women with breast cancer, inflammation in the tumor microenvironment, with local elevation in the expression of proinflammatory cytokines (such as tumor necrosis factor- $\alpha$ ), has also been associated with increased invasiveness and a poor prognosis [43]. Although all of the components of MetS have been linked with an increased risk of breast cancer in postmenopausal women in a previous meta-analysis, the combination of these components in MetS seemed to confer stronger association than individual components [44]. The key mechanisms and the exact molecular signaling pathways underling the association between MetS and poor prognosis in women with breast cancer deserve further investigation.

Our study has limitations, which should be considered when interpreting the results. Firstly, as a meta-analysis of observational studies, although we combined RR data after adjustment of potential confounding factors, we could not exclude other residual factors that may confound the association between MetS and recurrence of breast cancer, such as treatment with metformin or 
making diet and or exercise in breast cancer survivors to modify the components of the MetS, which have all been suggested to confer anticancer efficacy [45-47]. Secondly, MetS were diagnosed with various criteria in the included studies. Although these criteria were based on the same components for the diagnosis of MetS [7, 31, 32], the differences of the criteria may be a source of heterogeneous of the meta-analysis. Importantly, the prevalence of MetS may be varying according to the different criteria used for the diagnosis of MetS. For example, among 168 Spanish postmenopausal women with breast cancer, the prevalence of NCEP-ATP III defined MetS was 53.7\% [14], while another study showed that the prevalence of MetS defined by IDF criteria was 39\% in another cohort of postmenopausal women with breast cancer [13]. However, due to the limited datasets available, we were unable to determine the potential influences of the different diagnostic criteria for MetS on the outcomes of the metaanalysis (Additional file 1: Figure S1). Thirdly, it has been suggested that the potential pathophysiological association between MetS (such as insulin resistance and inflammation) and breast cancer may be affected by hormone status of the cancer [4]. Therefore, it is of clinical importance to determine the potential influence of HR status on the association between MetS and outcomes of breast cancer. However, only three of the included studies provided data stratified by HR status of the cancer $[16,19$, 20]. One focused on the status of estrogen receptor (ER) [16], one analyzed ER and progesterone receptor (PR) [19], and another one evaluated ER, HR and human epidermal growth factor receptor-2 (HER-2) [20]. The differences of the HRs analyzed in the above studies made it unable to perform a subgroup analysis with available data. Therefore, further large-scale prospective cohort studies are needed to determine the association between MetS and clinical outcomes in women with breast cancer of different HR status and of different menopausal status. Fourthly, due to the limited number of the included studies, result for the association between MetS and breast cancer related mortality should be interpreted with caution until further studies are available. Fifthly, the mean follow-up durations varied significantly across studies (from 2.4 to 11.1 years), and including very short followup studies may affect the outcome of the meta-analysis. In addition, menopausal status has been shown to affect the association between MetS and risk of breast cancer in a previous meta-analysis [44]. Similarly, in the MeCan (metabolic syndrome and cancer) project, MetS was associated with a decreased risk of incident breast cancer in women below age 50 with high body mass index, and with an increased risk of breast cancer mortality in women above 60 [48]. It remains unknown whether menopausal status may affect the association between MetS and prognosis in women with breast cancer, and further researches are needed. Finally, a causative relationship between MetS and poor prognosis in breast cancer should not be retrieved from our results. Future studies are needed to determine whether management of MetS in women with breast cancer could improve their clinical outcomes.

\section{Conclusions}

In conclusion, our meta-analysis showed that MetS may predict higher risk of cancer recurrence and mortality in women with breast cancer, particularly in Caucasians. Future studies are needed to clarify the potential influence of cancer HR status and menopausal status on the association between MetS and prognosis, and to determine whether management of MetS in women with breast cancer could improve their clinical outcomes.

\section{Supplementary information}

Supplementary information accompanies this paper at https://doi. org/10.1186/s13098-019-0514-y.

Additional file 1: Figure S1. Subgroup analyses for the association between MetS and recurrence of breast cancer according to the diagnostic criteria of MetS.

\section{Abbreviations}

MetS: metabolic syndrome; GC: gastric cancer; MOOSE: Meta-analysis of Observational Studies in Epidemiology; RRs: risk ratios; SE: stand error; NCEPATP III: National Cholesterol Education Program's Adults Treatment Panel III; IDF: International Diabetes Federation; HR: hormone receptors; IGF: insulin-like growth factor-1; ER: estrogen receptor; PR: progesterone receptor; HER-2: human epidermal growth factor receptor-2.

\section{Acknowledgements}

Not applicable.

\section{Authors' contributions}

PL, TW, CZ, MY, GL, JH, and WW. PL, TW, CZ, MY, GL, and JH carried out the acquisition and analysis of data. PL, TW, and WW performed the drafting and revising of the manuscript. PL and WW participated in the design. All authors have given final approval of the version to be published and everyone agreed to be accountable for all aspects of the work in ensuring that questions related to the accuracy or integrity of any part of the work are appropriately investigated and resolved. All authors read and approved the final manuscript.

\section{Funding}

This study was supported by the Natural Science Foundation of Hunan Province of China (Project number: 2018JJ2610) to Dr. Wei Wu.

\section{Availability of data and materials}

The available data and materials section refers to the raw data used in our study are included in manuscript with tables, figures and its additional files. All the authors agreed that the data could be shared if researchers required.

\section{Ethics approval and consent to participate}

All analyses were based on previous published studies, thus no ethical approval and patient consent are required. All previous published studies were approved by ethics committee respectively. 


\section{Consent for publication}

Not applicable.

\section{Competing interests}

The authors declare that they have no competing interests.

\section{Author details}

${ }^{1}$ Department of Breast Thyroid Surgery, The Third Xiangya Hospital of Central South University, No. 172 Tong Zi Po Road, Changsha 410013, China. ${ }^{2}$ Department of Hepatopancreatobiliary Surgery, The Third Xiangya Hospital of Central South University, No. 172 Tong Zi Po Road, Changsha 410013, China.

Received: 31 October 2019 Accepted: 27 December 2019

Published online: 29 January 2020

\section{References}

1. Harbeck N, Gnant M. Breast cancer. Lancet. 2017;389(10074):1134-50.

2. Barrios $\mathrm{CH}$, Reinert T, Werutsky G. Global breast cancer research: moving forward. Am Soc Clin Oncol Educ Book. 2018;38:441-50.

3. Torre LA, Bray F, Siegel RL, Ferlay J, Lortet-Tieulent J, Jemal A. Global cancer statistics, 2012. CA Cancer J Clin. 2015;65(2):87-108.

4. Rose DP, Gracheck PJ, Vona-Davis L. The interactions of obesity, inflammation and insulin resistance in breast cancer. Cancers (Basel). 2015;7(4):2147-68.

5. Laudisio D, Muscogiuri G, Barrea L, Savastano S, Colao A. Obesity and breast cancer in premenopausal women: current evidence and future perspectives. Eur J Obstet Gynecol Reprod Biol. 2018;230:217-21.

6. Kang C, LeRoith D, Gallagher EJ. Diabetes, obesity, and breast cancer. Endocrinology. 2018;159(11):3801-12.

7. Yamagishi $\mathrm{K}$, Iso $\mathrm{H}$. The criteria for metabolic syndrome and the national health screening and education system in Japan. Epidemiol Health. 2017;39:e2017003.

8. Li R, Li W, Lun Z, Zhang H, Sun Z, Kanu JS, Qiu S, Cheng Y, Liu Y. Prevalence of metabolic syndrome in Mainland China: a meta-analysis of published studies. BMC Public Health. 2016;16:296.

9. Grundy SM. Metabolic syndrome pandemic. Arterioscler Thromb Vasc Biol. 2008;28(4):629-36.

10. Eckel RH, Grundy SM, Zimmet PZ. The metabolic syndrome. Lancet. 2005;365(9468):1415-28.

11. Bhandari R, Kelley GA, Hartley TA, Rockett IR. Metabolic syndrome is associated with increased breast cancer risk: a systematic review with meta-analysis. Int J Breast Cancer. 2014;2014:189384.

12. Esposito K, Chiodini P, Colao A, Lenzi A, Giugliano D. Metabolic syndrome and risk of cancer: a systematic review and meta-analysis. Diabetes Care. 2012;35(11):2402-11.

13. Healy LA, Ryan AM, Carroll P, Ennis D, Crowley V, Boyle T, Kennedy MJ, Connolly E, Reynolds JV. Metabolic syndrome, central obesity and insulin resistance are associated with adverse pathological features in postmenopausal breast cancer. Clin Oncol (R Coll Radiol). 2010;22(4):281-8.

14. Lubian Lopez DM, Castillo Lara M, Rodriguez Rodriguez B, Butron Hinojo CA, Martinez Herrera A, Sanchez Borrego R, Mendoza Ladron de Guevara N. Metabolic syndrome and prognostic factors in postmenopausal breast cancer patients. Breast J. 2019;25(3):548-51.

15. Pasanisi P, Berrino F, De Petris M, Venturelli E, Mastroianni A, Panico S. Metabolic syndrome as a prognostic factor for breast cancer recurrences. Int J Cancer. 2006;119(1):236-8.

16. Berrino F, Villarini A, Traina A, Bonanni B, Panico S, Mano MP, Mercandino A, Galasso R, Barbero M, Simeoni M, et al. Metabolic syndrome and breast cancer prognosis. Breast Cancer Res Treat. 2014;147(1):159-65.

17. Calip GS, Malone KE, Gralow JR, Stergachis A, Hubbard RA, Boudreau DM. Metabolic syndrome and outcomes following early-stage breast cancer. Breast Cancer Res Treat. 2014;148(2):363-77.

18. Simon MS, Beebe-Dimmer JL, Hastert TA, Manson JE, Cespedes Feliciano EM, Neuhouser ML, Ho GYF, Freudenheim JL, Strickler H, Ruterbusch J, et al. Cardiometabolic risk factors and survival after breast cancer in the Women's Health Initiative. Cancer. 2018;124(8):1798-807.

19. Oh SW, Park CY, Lee ES, Yoon YS, Park SS, Kim Y, Sung NJ, Yun YH, Lee $\mathrm{KS}$, Kang HS, et al. Adipokines, insulin resistance, metabolic syndrome, and breast cancer recurrence: a cohort study. Breast Cancer Res. 2011;13(2):R34

20. Fan Y, Ding X, Wang J, Ma F, Yuan P, Li Q, Zhang P, Xu B. Decreased serum HDL at initial diagnosis correlates with worse outcomes for triple-negative breast cancer but not non-TNBCs. Int J Biol Markers. 2015;30(2):e200-7.

21. Muniz J, Kidwell KM, Henry NL. Associations between metabolic syndrome, breast cancer recurrence, and the 21-gene recurrence score assay. Breast Cancer Res Treat. 2016:157(3):597-603.

22. Grybach SM, Polishchuk LZ, Chekhun VF. Analysis of the survival of patients with breast cancer depending on age, molecular subtype of tumor and metabolic syndrome. Exp Oncol. 2018;40(3):243-8.

23. Tong YW, Wang G, Wu JY, Huang O, He JR, Zhu L, Chen WG, Li YF, Chen XS, Shen KW. Insulin-like growth factor-1, metabolic abnormalities, and pathological complete remission rate in HER2-positive breast cancer patients receiving neoadjuvant therapy. Onco Targets Ther. 2019;12:3977-89.

24. DeSantis CE, Ma J, Goding Sauer A, Newman LA, Jemal A. Breast cancer statistics, 2017, racial disparity in mortality by state. CA Cancer J Clin. 2017;67(6):439-48.

25. Stroup DF, Berlin JA, Morton SC, Olkin I, Williamson GD, Rennie D, Moher D, Becker BJ, Sipe TA, Thacker SB. Meta-analysis of observational studies in epidemiology: a proposal for reporting. Meta-analysis Of Observational Studies in Epidemiology (MOOSE) group. JAMA. 2000;283(15):2008-12.

26. Higgins J, Green S. Cochrane Handbook for Systematic Reviews of Interventions Version 5.1.0. The Cochrane Collaboration 2011, http://www. cochranehandbook.org. Accessed 12 Sept 2019.

27. Wells GA, Shea B, O'Connell D, Peterson J, Welch V, Losos M, Tugwell P. The Newcastle-Ottawa Scale (NOS) for assessing the quality of nonrandomised studies in meta-analyses. 2010, http://www.ohri.ca/programs/ clinical_epidemiology/oxford.asp. Accessed 12 Sept 2019.

28. Higgins JP, Thompson SG. Quantifying heterogeneity in a meta-analysis. Stat Med. 2002;21(11):1539-58.

29. Chuang SC, Lee YC, Wu GJ, Straif K, Hashibe M. Alcohol consumption and liver cancer risk: a meta-analysis. Cancer Causes Control. 2015;26(9):1205-31.

30. Egger M, Davey Smith G, Schneider M, Minder C. Bias in meta-analysis detected by a simple, graphical test. BMJ. 1997;315(7109):629-34

31. Grundy SM, Cleeman Jl, Merz CN, Brewer HB Jr, Clark LT, Hunninghake DB, Pasternak RC, Smith SC Jr, Stone NJ. Implications of recent clinical trials for the National Cholesterol Education Program Adult Treatment Panel III guidelines. Circulation. 2004;110(2):227-39.

32. Alberti KG, Zimmet P, Shaw J. Metabolic syndrome-a new world-wide definition. A Consensus Statement from the International Diabetes Federation. Diabet Med. 2006;23(5):469-80.

33. Maksimovic MZ, Vlajinac HD, Radak DJ, Marinkovic JM, Jorga JB. Prevalence of the metabolic syndrome in patients with carotid disease according to NHLBI/AHA and IDF criteria: a cross-sectional study. BMC Cardiovasc Disord. 2012;12:2.

34. Park BJ, Shim JY, Lee HR, Jung DH, Lee JH, Lee YJ. The relationship of platelet count, mean platelet volume with metabolic syndrome according to the criteria of the American Association of Clinical Endocrinologists: a focus on gender differences. Platelets. 2012;23(1):45-50.

35. Santorelli ML, Hirshfield KM, Steinberg MB, Lin Y, Rhoads GG, Bandera EV, Demissie K. Racial differences in the effects of comorbidity on breast cancer-specific survival. Cancer Causes Control. 2017;28(8):809-17.

36. Wan D, Villa D, Woods R, Yerushalmi R, Gelmon K. Breast cancer subtype variation by race and ethnicity in a diverse population in British Columbia. Clin Breast Cancer. 2016;16(3):e49-55.

37. Huo D, Hu H, Rhie SK, Gamazon ER, Cherniack AD, Liu J, Yoshimatsu TF, Pitt JJ, Hoadley KA, Troester M, et al. Comparison of breast cancer molecular features and survival by African and European ancestry in the cancer genome atlas. JAMA Oncol. 2017;3(12):1654-62.

38. Colonna SV, Douglas Case L, Lawrence JA. A retrospective review of the metabolic syndrome in women diagnosed with breast cancer and correlation with estrogen receptor. Breast Cancer Res Treat. 2012;131(1):325-31.

39. Mendonca FM, de Sousa FR, Barbosa AL, Martins SC, Araujo RL, Soares R, Abreu C. Metabolic syndrome and risk of cancer: which link? Metabolism. 2015;64(2):182-9.

40. Jung SY, Ho G, Rohan T, Strickler H, Bea J, Papp J, Sobel E, Zhang ZF, Crandall C. Interaction of insulin-like growth factor-I and insulin 
resistance-related genetic variants with lifestyle factors on postmenopausal breast cancer risk. Breast Cancer Res Treat. 2017;164(2):475-95.

41. Crespi E, Bottai G, Santarpia L. Role of inflammation in obesity-related breast cancer. Curr Opin Pharmacol. 2016;31:114-22.

42. Kim EJ, Choi MR, Park H, Kim M, Hong JE, Lee JY, Chun HS, Lee KW, Yoon Park JH. Dietary fat increases solid tumor growth and metastasis of 4T1 murine mammary carcinoma cells and mortality in obesity-resistant BALB/c mice. Breast Cancer Res. 2011;13(4):R78.

43. Goldberg JE, Schwertfeger KL. Proinflammatory cytokines in breast cancer: mechanisms of action and potential targets for therapeutics. Curr Drug Targets. 2010;11(9):1133-46.

44. Esposito K, Chiodini P, Capuano A, Bellastella G, Maiorino MI, Rafaniello C, Giugliano D. Metabolic syndrome and postmenopausal breast cancer: systematic review and meta-analysis. Menopause. 2013;20(12):1301-9.

45. Faria J, Negalha G, Azevedo A, Martel F. Metformin and breast cancer: molecular targets. J Mammary Gland Biol Neoplasia. 2019;24(2):111-23.

46. Dieli-Conwright CM, Wong L, Waliany S, Bernstein L, Salehian B, Mortimer JE. An observational study to examine changes in metabolic syndrome components in patients with breast cancer receiving neoadjuvant or adjuvant chemotherapy. Cancer. 2016;122(17):2646-53.

47. Nichols HB, Trentham-Dietz A, Egan KM, Titus-Ernstoff L, Holmes MD, Bersch AJ, Holick CN, Hampton JM, Stampfer MJ, Willett WC, et al. Body mass index before and after breast cancer diagnosis: associations with all-cause, breast cancer, and cardiovascular disease mortality. Cancer Epidemiol Biomarkers Prev. 2009;18(5):1403-9.

48. Bjorge T, Lukanova A, Jonsson H, Tretli S, Ulmer H, Manjer J, Stocks T, Selmer R, Nagel G, Almquist M, et al. Metabolic syndrome and breast cancer in the me-can (metabolic syndrome and cancer) project. Cancer Epidemiol Biomarkers Prev. 2010;19(7):1737-45.

\section{Publisher's Note}

Springer Nature remains neutral with regard to jurisdictional claims in published maps and institutional affiliations.
Ready to submit your research? Choose BMC and benefit from:

- fast, convenient online submission

- thorough peer review by experienced researchers in your field

- rapid publication on acceptance

- support for research data, including large and complex data types

- gold Open Access which fosters wider collaboration and increased citations

- maximum visibility for your research: over $100 \mathrm{M}$ website views per year

At BMC, research is always in progress.

Learn more biomedcentral.com/submissions 